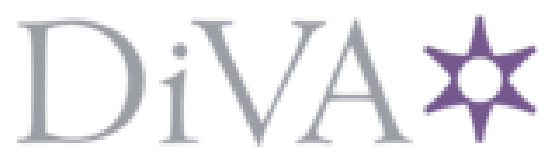

http://www.diva-portal.org

\title{
Postprint
}

This is the accepted version of a paper published in International Journal of Managing Projects in Business/Emerald. This paper has been peer-reviewed but does not include the final publisher proofcorrections or journal pagination.

Citation for the original published paper (version of record):

Fowler, N., Lindahl, M., Sköld, D. (2015)

The Projectification of University Research: A study of resistance and accommodation of projectmanagement tools \& techniques.

International Journal of Managing Projects in Business/Emerald, 8(1)

http://dx.doi.org/10.1108/IJMPB-10-2013-0059

Access to the published version may require subscription.

N.B. When citing this work, cite the original published paper.

Permanent link to this version:

http://urn.kb.se/resolve?urn=urn:nbn:se:uu:diva-240688 


\author{
Nina Fowler \\ Marcus Lindahl \\ David Sköld *
}

Division of Industrial Engineering \& Management

Department of Engineering Sciences

Uppsala University, Sweden

* Corresponding author: david.skold@angstrom.uu.se

\title{
The Projectification of University Research
}

\author{
- A study of resistance and accommodation of \\ project management tools and techniques
}

\begin{abstract}
Purpose: The paper discusses and critically examines how formal project management tools and techniques affect the organization of university research.

Design/methodology/approach: The paper is empirically grounded and explores how university researchers respond to an increasing emphasis on formalized Project Management methods to manage research work conducted within the university. The empirical material consists of 20 interviews with research staff working with engineering, natural and medical sciences at Uppsala University, Sweden. Describing how PM techniques are increasingly imposed upon the researchers, the article analyses different modes of relating to the formalized toolsets, and discusses their accommodation and resistance within academia.
\end{abstract}

Findings: One key finding is how the PM formalization is resisted by partial accommodation and containment. This can be described in terms of an enactment of a front and a backstage of the research organization. At the front-stage, formal PM technology and terminology is used by specially appointed research managers as means of presenting to funding agencies and other external parties. At the backstage, researchers carry out work in more traditional forms.

Practical implications: The findings indicate a challenge for research to comply with increased project management formalization and secure on-going open-ended research. Secondly, the paper points toward a risk of young researchers being nudged out into "frontstage" administration with little chance of returning to "backstage" research.

Originality/value: This paper builds upon a growing area of the critical analysis of project management practice, offering insights into the tension between the values and norms of university research and an on-going formalization of project management in some organizational contexts.

Paper type: Research paper

Keywords: Project management, Project tools \& techniques, Management of university research, Resistance, Accommodation, Front-stage - Backstage 


\section{Projectification of University Research}

Leading and managing knowledge intensive organizations populated by scientists and engineers has long been conceived as a major challenge (see, e.g., Etzioni, 1964). Such highlevel knowledge workers have often been found to be inimical to direct supervision, and to other traditional means of control aimed, for instance, at standardizing the outputs of their work or the processes going into it (Mintzberg, 1980). As Gideon Kunda (1992) reports in Engineering Culture, this has called for alternatives, with Kunda himself famously foregrounding cultural management programs and normative control measures, which operate by inducing common norms and values, and by regulating shared aims and identities within the work force; and with Kim Clark and Steven Wheelwright (1992) pointing towards project management (PM) as yet another promising means for leading "heavyweight" developments. While cultural management and reengineering programs have lost quite a bit of legitimacy over the last decades, in the light of a growing concern with diversity issues, for instance (see, e.g., Barker, 1993; Fleming \& Sturdy, 2011), the tools and techniques of PM have often been posited, however, as less obtrusive, and they have steadily been gaining ground. One might even say that PM has emerged as somewhat of a universal remedy for leading high-level knowledge work - a cure that has promoted itself as being applicable to a wide range of sectors, and attending to more or less any challenge associated with the explorative, irregular and creative work carried out by scientific or engineering experts. This in a way that has made it seem dissociated from questions of power and politics. As Damian Hodgson (2002: 804) has put it, "the field of Project Management has promoted itself as a universal and politically-neutral toolkit of techniques appropriate for any type of activity in any sector, enabling the tight control of discontinuous work processes, with particular potential for the control of expert labour."

In Sweden, the tools and techniques inherent to traditional, linear and instrumental PM have in recent years made a subtle entrance also into academia, and particularly the scientific laboratory, with "the Project" having become the preferred vehicle of choice for controlling government-sponsored research activities. Spending approximately $€ 4.4$ billion annually, or $1.3 \%$ of the GDP (HSV, 2011), the wide range of state-governed funding bodies supposedly need measures that allow them to keep a close account of their investments, and guarantee that the financial resources they have distributed are subject to careful and efficient management - measures that extend the control without interfering with the research agenda or the research results, and allow researchers to retain their academic freedom. While the PM field of today could be said to accommodate two major paradigms: traditional linear PM, and agile PM techniques, the project model that to increasing extents is being imposed on the academic realm to monitor scientific progress and expenditures, and to transform funds to research results, belongs - as the article will show - to the former. That is, to a PM paradigm which has sprung out of traditional industry, and particularly out work oriented towards traditional product development.

Despite the hold that this organizational form is taking over the academic realm, there has been little debate concerning this development; neither the status nor the role of the prevailing traditional model of PM has been subject to much critique within this particular context. As indicated above, however, the universal applicability and the neutrality of traditional PM tools and techniques have come under increasing scrutiny over the last decade or two by a more critically minded cadre of PM scholars. A growing body of research has for instance begun to question to what extent they are in fact capable of combining an efficient resource management with high-level knowledge work, which is of an experimental and indeterminate character (see, e.g., Lenfle, 2008; Lenfle \& Loch, 2010). With their focus on the execution of predefined tasks, are traditional PM tools and techniques in fact suitable for leading iterative research that is ridden by uncertainty, and whose conceptual framing and future direction is constantly subject to renegotiation/re-formulation? And immediate suitability aside, are they in fact as politically neutral as they have made themselves out to be? Or does the imposition of this kind of management control system - as a number of voices have indeed indicated, Hodgson (2002; 2005) among them - entail more subtle and complex forms of power; a form of control, which in fact conceals its political and indeed also 
ethical underpinnings and implications? Does it make out another form of normative control, which may in fact discipline and strip its constituents of their distinctiveness and undermine foundational components of scientific practices; does it make out a form of control that may in fact corrupt guiding values and upset established power relations within the academic institution? Does PM constitute a field or a body of knowledge whose imposition will generate, in its wake, corporeal as well as organizational "bodies of knowledge" that internalize its tools and techniques for conducting research, and give precedence to execution-oriented thinking? - Project workers-researchers subjected to the disciplining powers of PM, deprived of experimental and creative freedom? - Unanticipated organizational setups for handling the projectification of life in the laboratory, potentially altering extant power relations within the academic institution?

In recent years, a growing body of literature has begun to interrogate the relationship between power and PM, addressing these questions, and focusing attention on the developmental tendencies briefly indicated here. Seeking to build upon and extend such critical inquiries, this article explores how PM is making its way into the realms of university research, with the aim of conceptualizing some consequences of an escalating projectification of the activities taking place within the university - or indeed an escalating PM-ification of this institutional realm. For the academy has of course been referring to the work carried out within this domain in terms of projects for a long time, but in a loosely defined sense, and without implying any particular management control structure. What interests us, however, is how traditional PM, as a particular model for organizing and conducting project work, is handled within the university, and how it redistributes power within this institutional domain.

\section{Particularities of Sweden and Uppsala}

In Swedish academia, PM methods, tools and techniques are unequivocally called for to structure, guide and control research efforts. Grant applications are organized as project charters, requiring timelines, milestones, Key Performance Indicators (KPIs), strategies for dispersions of results, and so forth, before the designated research task has even been initiated; and the appointment of typical professional PM responsibilities, such as "Project Manager" and "Work Package leader", are incorporated into the application frameworks. Interviews conducted with researchers indicate that some do indeed feel compelled to appropriate and use PM methodologies to become viable for funding. The PM methodologies are reflected, moreover, in reporting procedures, and in the handling of the research on a daily basis. As support for the latter, universities promote specific two, three, or four day PM courses, directed towards junior faculty - supposedly with the aim of preparing them for the challenge of running their own projects, and making them more competitive for funding and often given by external consultants who operate in close connection to national or international PM associations. One such Swedish training and consultancy company has for instance been offering traditional basic PM courses to Uppsala University (UU) staff for at least a ten-year period, to a value of more than 600 kEuro between 2003 and 2012 (among its clients one can also find Lund University, Stockholm University, Gothenburg University, The Royal Institute of Technology, Chalmers Technical University, the Swedish University of Agricultural Sciences, and since 2010, also the Swedish Research Council).

We thus appear to be witnessing a projectification, or PM-ification, of university research that is imposed on the academic setting through application frameworks, through the taxonomies guiding the research efforts, through daily coordination and reporting activities, and through courses addressing young researchers - which even appear to be aligned across universities as well as certain funding bodies. As will be discussed later on, this phenomenon does not in any way appear to be characteristic only of Swedish universities, which various different kinds of EU-projects bear witness of; the application and reporting procedures associated with both the European Commission's Seventh Framework Programme and the Knowledge and Innovation Communities within the European Institute of Technology rather seem to epitomize such projectification or PM-ification. 


\section{How do PM tools and techniques affect the organization of university research?}

Presumably, the developments sketched out above set the stage for a range of conflicts concerning the so-called identity of the researchers and their organizations, and the powers guiding them. More specifically, they set the stage: 1) for conflicts concerning the role of the researcher and the role of the project leader, between researchers perceiving themselves and their research activities as being involved, on the one hand, in an open-ended knowledge creation process and a process of most instrumental and tightly controlled knowledge/value production; 2) for conflicts concerning the interests and ideals that determine these processes, between sacred epistemological ideals, and execution-oriented thinking seeking to reduce uncertainty and attain a predefined set of deliverables; and 3) for conflicts concerning the organization of temporary activities and permanent practices within the scientific institution, between front-stage presentation, evaluation and administration, and backstage preparation, iteration and reorientation of the scientific work. These conflicts are neither distinct nor dualistic, to our view, but rather intertwined and folding onto one another. For instance, in discourses on academic career management, subscribing to PM - i.e., attaining PM skills and possibly also certification by attending a course, and actually taking on the role as Project Manager - is posited as a means for making it as a researcher, and establishing your own independent research platform. How PM imposes itself on the scientific realm, and how the potential conflicts this involves are in fact handled and reconciled, are thus questions that involve convoluted ethical and political dimensions. Acknowledging these aspects is, to our view, central for understanding the powers at play in a projectification of academia. Consequently, and contrary to the apolitical image conveyed by the field of PM, this article suggests that the projectification of the academic realm outlined above is in fact highly obtrusive, subjecting university research to the managerial fantasy of being able to combine explorative, indeterminate, creative research work with rational, instrumental, executionoriented work processes that unfold in a linear manner without losing anything essential in the process; and of sustaining difference and uniqueness across disciplines, and fostering leadership as well as learning, whilst at the same time intensifying cross-disciplinary collaboration, through the sheer organizational form provided by PM. With the management control system residing at the heart of this fantasy being promoted as a means for retaining academic freedom and autonomy, and PM courses being posited as an opportunity for learning to master these means and safeguard these interests, it is arguably one that may be hard to resist due to the promises associated with it, and whose disciplining power is therefore quite inveigling. With application frameworks and taxonomies, as well as reporting structures being built around PM methodologies, it is a fantasy, moreover, that has to be dealt with also if one does not really buy into its promise - at least if one wants to remain in business, in academia.

Taken together, these developments, and these initial observations concerning the obtrusive and perhaps even seductive nature of this management control system, raise questions of how PM, more specifically, imposes itself on scientific and engineering research, and how this is dealt with by individual researchers as well as research collectives. Drawing on an empirical, interview-based study of university researchers pursuing collective research projects in engineering and in the natural and medical sciences, the article inquires into the workings of the disciplinary regime briefly sketched out above, and explores the strategies deployed to resist and accommodate the PM tools and techniques in these settings. What modes of accommodating, rationalizing, and legitimizing the utilization of PM methodologies/technology are deployed by the researchers, and what modes are used to resist, criticize, and detach themselves from it? How may the potential conflicts and contested fantasies discussed above affect and perhaps also divide and stratify researchers on an individual as well as collective level? How does the research community respond to new generic PM initiatives? 


\section{Theoretical and Methodological Considerations}

In recent years, a critical perspective on professionalization and PM has drawn attention to how the escalation of project organizations, and the deployment of PM tools in knowledge intensive organizations, has developed into somewhat of a professional discipline in and of itself. In doing so, the critique has pointed out that such a development implies a higher degree of supervision and control and has far greater disciplining effects than is usually acknowledged by PM discourse. James Barker (1993) has for instance argued that a projectification of work has entailed a shift from hierarchical and bureaucratic organizational systems, by which control is exerted through standardized tasks and work processes, to "concertive systems" or "concertive forms" of control, exercised through peer-to-peer supervision in self-managing teams. Contrary to the notion that project work entails a greater degree of freedom than the rational control systems examined by for instance Max Weber (1905/2009), Barker suggests that concertive systems in fact are strengthening control in many cases - "tightening the iron cage," as it were. With reference to Michel Foucault's work on panoptic power structures, Beverly Metcalfe (1997) has also emphasized how numerous technologies for calculating and evaluating the contribution of specific project members in fact leads to increased supervision and control, and a distributed form of surveillance of the individuals subjected to this organizational form.

Drawing more heavily on Foucault's work, and particularly his earlier writings on power/knowledge Hodgson (2002) has moreover showed how this form of managerial knowledge is inextricably tied up with power as a discipline unto itself. One that subjects not only project members, but also project managers to rather obtrusive, albeit indirect, forms of control. Far from "an 'objective' and 'abstract' body of knowledge," which has detached itself from power and authoritarian means of control by leveling the organization and allocating resources based on specific competences, as mainstream PM discourse often implies, power has rather come to be embodied in this discipline itself, according to Hodgson's analysis. For as a professional body of knowledge, which harbors an array of different toolsets that are put to use in the professional realm, it fosters a certain construction and ordering of the world that is aligned with the logics endorsed by this apparatus. To an increasing degree, models, methods and techniques, principles and formulas, and dedicated concepts and terminology, which are part and parcel of this knowledge discipline, come to be taken as true representations of organizational and intersubjective phenomena.

Hodgson (2002) goes on to argue that the particular workings of this knowledge formation foster a belief in the transferability of PM tools and techniques from one context to the next. It hegemonizes work processes by monopolizing the representation of them, sanctioning certain ways of articulating organizational processes while delegitimizing others. In the wake of such developments, conducting and constituting oneself according to professional ways of working, and mastering the tools for doing so, becomes a prestigious endeavor, entailing improved security and status. And although the attitudes towards such developments may be highly ambivalent, the effect, Hodgson suggests, is nevertheless that PM skills and expertise is made into a central component for the formation of professional identities, and for instituting new hierarchical orders.

These Foucauldian interventions have thus pointed to how PM can be understood as a field of knowledge whose power is one that becomes obscured as it gets embodied - in a certain body of theoretical and practical knowledge, but also in an organization, and in all those corporeal bodies subjected to it. As this knowledge gets performed by subjects who have either internalized a certain conduct, or engaged in parodying or otherwise contesting measures against it, the effects are difficult to distinguish, and ridden with ambiguity (see also Hodgson, 2005). What further obscures the power of this discipline, presumably, is the way in which a managerial discourse on post-bureaucratic control (see, e.g., Adler, 2001; Benveniste, 1994; Kanter, 1990; Savage, 1996) has hailed it as a move away from suppressing bureaucratic forms of control (cf. Maravelias, 2003). It has not merely posited itself as a neutral form of organizing, but as a desirable one, which holds a promise of selfactualization, and personal/professional development at work; one that is capable, for instance, of accommodating and advancing specific capabilities and competencies, while at 
the same time integrating them in collaborative efforts, as we saw in the previous section. Freed also of the manipulative dimensions of cultural management, and offering an everwidening range of toolsets claiming to extend the scope and increase the adaptability of PM by and large, this increasingly fragmented field has arguably come with an ethical imperative or a moral injunction to enjoy the different fruits it has to offer. Although Hodgson leaves this ethical dimension aside, much of his analysis appears to rest on the assumption that the disciplining power of PM comes from its appeal - and from an ambivalent desire to submit to such a regime. In this respect, PM can be understood as a far more obtrusive management control system than it usually is - one that also gains quite a bit of power from convoluted ethical and political dimensions.

If PM gains some of its overall power and appeal from how it ties into the notion of professionalism, and being part of a post-bureaucratic movement that surpasses traditional bureaucratic organizational forms, this relative value does not have as much purchase to researchers within the university. Such an appeal even appears to run counter to many values typifying university research, since the academy has often been viewed as one of the most traditionalistic, yet autonomous of sectors. Characterized by its own rituals and rigid ranking systems, it has been portrayed as an institutional realm that is held together by what Max Weber might have termed a clan-like power structure, with distinguished professors serving as patriarchal figures who take quite a bit of prestige in demonstrating their idiosyncrasies as well as their autonomy, and operating more as adhocracies or very decentralized bureaucracies, where decision making power is located in the hands of respected and highranked research leaders, than centralized bureaucracies (see, e.g., Mintzberg, 1980). Granting PhD students the possibility to develop their scientific undertakings as well as themselves, the notion of independence and autonomy is not only a privilege of senior staff, but spans across academic hierarchies also to junior researchers. Some, like Tony Becher and Maurice Kogan (1992: 100), would even claim that this makes "out an essential sociotechnical condition for good academic work".

To what extent the academy, and academics by and large, actually are as autonomous as these accounts maintain, and seem to prescribe, is of course debatable. Worth noting, however, is that when Mary Henkel (2005) revisits and problematizes the relationship between academic identity and autonomy, she finds the latter to be a central component of the self-perception of professional academics, and something that is constructed through a long process of internalizing values, aspirations, sense of meaning and worth, language, theories and knowledge, which starts in the early phase of the PhD process (see also Henkel, 2007). Rather than splitting hairs about the actual degree of freedom and autonomy characterizing the academic setting, or losing ourselves in a debate on the extent to which academics are already subject to self-disciplining knowledge regimes, we might thus conclude that the fantasy of autonomy has loomed long over the academic setting. And in posing as a neutral tool for handling high-level knowledge work, PM appears, incidentally, to have tuned in to this fantasy, and positioned itself as a means for attaining more of it.

Now, these observations and theoretical considerations arguably raise a number of questions concerning the import of PM tools and techniques to academic settings. For how do specific researchers and research groups relate to the seemingly contradictory PM fantasy that is imposing itself on academia? How do they handle, and actually deal with the escalating projectification that it entails, and how do these measures seem to affect the power relations, the professional roles, and the identities or self-perceptions at work in these settings? What happens when this form of management control system comes stealing into academia?

To explore these questions the article builds on interviews with a range of different researchers and project managers/administrators within the natural sciences and engineering sciences at UU. The interviews were planned as semi-structured conversations where the aim was to have the respondent talk in their own words about their work and their view on research. Aside from a general interest in their perspective of being a researcher and doing research work we were particularly interested in their experiences of project management within and across their academic borders. The interviews were conducted in Swedish and English during 2012 and 2013, and transcribed in the same languages. 
During the interviews, participants were thus asked to describe their work, motivations and reporting activities with relation to the theme of project management. Academics from a range of disciplines, including neuroscience, material physics, informatics, immunology and cancer research, were interviewed in half hour to hour-long sessions. The positions and length of academic careers varied from post-doctoral researchers (eight) to professors (three), and included assistant professors (one), lecturers (two), curators (two), and (four) self-defined co-coordinators (two with Masters degrees, two with multiple years of post-doctoral experience). Potential participants were identified in a number of ways, from registration lists for the course Practical Project Management (swe. Praktisk Projektledning) offered by the university, to an open invitation to researchers at the Faculty of Science and Technology. Of those interviewed, twelve had taken the course.

\section{Case File: Project Management Liturgy at Work}

In the interviews conducted, nearly all respondents were reluctant to define their activities as being project-based. Rather they positioned their own activities against such an organizational form, contending that projects must surely be conducted in a much more prescribed manner outside the university. Despite this hesitation to identify their ways of organizing work with formalized PM methodologies - typically claiming that: "we don't work like that!" - the respondents were nevertheless inclined to talk about their work in project terms, and in a vernacular that appears to be heavily influenced by the PM liturgy. In particular, three disciplining instances stand out in this regard: funding applications, reporting activities, and the PM education program itself. Recurring in the interviews as distinct themes, they appear to have had a particular impact on the respondents' way of relating to their research, and make out three different disciplining forces at play in the projectification of the academic setting.

\section{Grant applications and funding frameworks}

The most powerful force is arguably exerted by the sheer structure of research applications. Take, for instance, the instructions from the Swedish Research Council, the role of which is to fund basic research. The instructions for how to organize an application are very specific, requiring the applicant to present their proposed research under a predefined set of categories (see Figure 1). These categories are most generic - the same for the natural sciences, humanities, engineering sciences and the social sciences - and they are all presented as compulsory components of any kind of application. The instructions and the application formats are very similar, moreover, across different funding bodies, and across different kinds of research proposals. As can be note from Figure 1, applications for conducting basic research backed by the Swedish Research Council follow the same basic structure as grant applications to the framework programs launched by the European Commission.

\section{Research program (Appendix A)}

Appendix A should consist of a brief but complete description of the research objective on no more than ten A4 pages, including references. Please note that any pages in excess of the number allowed will not be considered in the evaluation.

The research programme, as well as other appendices, should be written in English as the Swedish Research Council uses international reviewers.

The research programme must include the following information under separate headings:

Purpose and aims. Present the overall purpose and specific goals of the research project (or equivalent)

Survey of the field. Summarize your own and others' research, as well as previous findings in the research field. Provide key references. 
Project description. Summarize the project's design. Describe theories, methods, timetable, implementation, as well as the function of co-workers (if any) in the project.

Significance. Describe the project's significance to the research area, especially with regard to innovation and originality.

Preliminary results. Describe your own experiments and pre-studies in the research area.

Figure 1: Streamlined presentation format for research project, excerpt from Swedish National Research council

To follow these guidelines, and to make oneself eligible and attractive for funding, is to narrate the research in PM language, and adapt to its specific requirements. Timelines, responsibilities, work packages, reporting structures, budgets, and so forth, are all central components in the PM toolbox, and must be accounted for in order for the application to pass the first instance in the assessment process, and be qualified for peer-review, possibly a second round, and ultimately for funding. Any application that is not fully aligned with the above-mentioned structure and that does not contain the prescribed content runs the risk of being disqualified from further consideration:

"In most cases yes. I mean in the EU projects - the Seventh Framework projects - there are deliverables specified, and you're supposed to have a plan for the impact of the research, and that's also the case for most of the other projects [...] So, most of our projects are rather well defined in terms of deliverables and things." Coordinator, Immunology, Genetics and Pathology

"Yeah, usually they write it in the announcements and then they also judge the application, based on what it is striving to. [...] So you adjust yourself and whatever you apply for." Senior lecturer, Nanotechnology and functional materials

A similar disciplining process can be observed in the mandatory reporting instructions, in case a grant is actually received. Distinct regulations organize and align both the content and the language by which the research is to be communicated. And what will be evaluated may for instance be stipulated by the goals/items shown in Figure 2.

\subsubsection{Evaluable goals}

The entire program will be evaluated for the following items:

- Assets of industrial production-related R \& D in Sweden

- The degree of collaboration in the automotive industry and between industry and academia (college, university, institute)

- The scope of the project results used to improve the participants' production systems

- The scope of the successful implementation of demonstration projects

- The number of new academic degrees in relevant fields

- The number of new courses for students, graduate students or professionals

- Number of industrial workers who have been significantly enhanced skills through the program's auspices

- The number of new patents and numerous published industry standards

Each of the activities and projects shall be specific, measurable objectives that are related to the content of the individual project. These goals are to operate in the same direction as the MERA program's overall objectives. Individual projects do not work on all assessable objectives for the program. 
In addition, the program is evaluated on qualitative items such as:

- Impact on the Swedish technology development and the Swedish production system's competitiveness,

- How far the program has helped to increase the quality of the production engineering education in relevant engineering program.

Figure 2: Standardized project output KPIs, excerpt from Swedish Research Council guidelines

\section{Practical project management education}

Funding and reporting aside, formal disciplining processes are a significant factor in many of the views expressed by the participants. As mentioned initially, one such process is that of project management education. Over at least a ten-year period, UU has been one of the largest single clients of a professional PM consultancy and training company, sourcing a three or four-day course in practical project management approximately twice a year. Directed both to interested research faculty and university administrators, the course is composed of PMI-inspired sessions, and promises to provide practice-oriented tools, techniques and terminology to enable the apprentice to make use of the project form in everyday work activities, or to run and manage projects that are more clearly defined.

The university heavily subsidizes the course. Of the total fee of approximately 2000 Euros, one tenth is paid by the participants' own department. The remainder is paid by the university, centrally. The two courses typically provided each year accommodate approximately 30 students each time, and there is a substantial mix of participants, with attendees ranging from full professors to PhD candidates and full time administrators, including those only within academia and others who are involved in spin-off organizations. The majority of participants over the last two courses are however, $\mathrm{PhD}$ candidates, full time project administrators and young researchers who aspire to become research leaders in the future.

A slightly paradoxical observation emerging from our material is how the respondents rationalize their participation in the course. Especially for the younger faculty, the PM course is a CV-enhancing paragraph, similar to the courses in pedagogy and in tutoring $\mathrm{PhD}$ students. However, whilst the latter courses are a requirement for a permanent position and often appreciated as supporting a teaching career, project management or project coordination positions are not considered to be of any prestige or provide any visible leverage within the academic hierarchy.

\footnotetext{
"Honestly, I wanted to have it in my CV. That [is why] I took the course. But I think that I appreciated it. I think I learned a lot of things. But if you apply for money its good to say I want to have money for a project and I actually have experience in that." Assistant Professor, Applied Materials Science

“[...] but I think that sometimes it's a little bit of a waste of time, and I sit there and I could be here and supervise instead, but I mean it looks good and I'm sure I got something out of it.” Researcher, Applied Materials Science
}

A common theme among the respondents is the perceived tension between the course view on projects and project management, and what these notions tend to mean and imply in the daily life of the participants. A researcher with past experience of taking the course, and a researcher on the 2012 course both described how their respective classes had argued with the teacher about the relevance of the course to their research activities and requirements. The time that passed between these two incidents might suggest that the course is taught according to industry PM expectations and the course designers are unable to alter the tools and/or teaching to better relate to the academic environment.

“[...] those course are a lot of times made for companies. [...] University is, I can’t really explain, but its like university is very different from companies [...] Sometimes that they 
talk about in this project management courses, how you report, and they talk a lot about this hierarchical structure and how, and that doesn't really apply in the same way I think at the university." Researcher, Applied Materials Science

To some degree though, especially among younger researchers, PM techniques are seen as something that could make research more efficient, as discussed earlier. Several respondents conclude that they would benefit from more structure but as long as some senior research leader is calling the shots, the "old" fuzzy way of work would continue. The need for better organization seems to rest on two pillars. One is a suppressed feeling of

mismanagement and fuzziness of senior research leaders. Secondly, there is a perception that research projects within both biology and engineering are becoming larger, incorporating more people and research groups but also more universities and industrial organizations. Thus, there is an increased "functional" need of more strict coordination and organization.

\section{We always talked about projects...}

One observation that we find quite striking is that the entire notion of project is unstable and quite heterogeneous. Particularly, there are several competing meanings of what a project is with regard to scope as well as time, depending on whether or not the term is used in its PM meaning or in a more local practice-related context. A substantial majority of those interviewed found it challenging to define their activities as project-based in a strict sense of the term, and were confident that projects unfold in a much more prescribed manner outside of the university environment - instead positioning their own activities against this. Although some only had an academic career, most had contact with industry in one-way or the other.

The respondents were asked to describe a project they were working on, providing details such as financial scope, the number of researchers involved, external collaborations and time span. The most commonly noted characteristic of the academic project was the absence of a fixed start or end time, this being a feature distinguishing academic work from industry projects. The closest those interviewed would come to articulating a start date was the time of funding being approved or a PhD student admitted. The finish date would coincide with an article being published, a report being submitted to financers or a $\mathrm{PhD}$ thesis being defended - although the researchers would hardly identify these activities as projects in the traditional PM sense of the term.

The perceived duration of a project is typically aligned with how the project purpose is understood. The shortest project is for instance defined in terms of a paper, and so the research goals that are pursued become translated into the effort of article writing and publishing.

\footnotetext{
"Does it have a beginning? Does it have an end? I know a project is supposed to have a clear beginning and a clear end, that's not how it works here, so in the strict sense of what a project is, it's not really a project. But we use that word all the time, and well, it sort of has an end right now since we submitted the paper, but we also know how to continue with this project. But you can call that the next project then I guess." Researcher, Neuroscience
}

A second, and different project duration, is linked to the financial year. This is not so much connected to outcome, but to administrative structure. This coincides with the process of funding, particularly for researchers with a doctorate who have a non-permanent research position; such personnel are funded annually.

"Well the Stint project is a three-year project where I get money for three years, the Vinnova is it three or four years, I can't remember. It's either three or four years on that one as well." Researcher, Applied Materials Science

A third, stable project duration uses the calculative base of a $\mathrm{PhD}$ candidate, which is a four or five-year project depending on the funding solution specified. It can be noted that this duration module actually pragmatically defines the duration of larger projects, for instance a project run by a center. A senior professor in material sciences explained: 


\begin{abstract}
"It is not well defined, this is via a center and this means that the center has the freedom to control project duration, the center is a long time. We have two graduate students where the idea is that they should be able to study for a $\mathrm{PhD}$ on this project. So we can guess that it will be just as far. So a five-year project duration. But it is by no means well defined." Professor, Microsystems Technology
\end{abstract}

For post-doctoral researchers and professors the interviews bear witness of a tendency to give a more personal and intellectually based definition of the project. These individuals are interested in the development of their own as well as their entire research fields' understandings of a scientific phenomenon. This longer-term view is reflected in the repeated use of the word project to describe researchers' activities whilst positioning those same activities against what the researchers perceived industrial projects to be. The use of the term project in this way might suggest a more abstract, undisciplined understanding of the academic world:

"Well then, it's research, we call it the project although it is perhaps not projects. It's little different projects [...] There are various projects, some are as under one umbrella, one can say. So it is several projects in one." Assistant Professor, Applied Materials Science

As any scholar of projects and project management knows, there are many types of projects: long ones and short ones, unique and repetitive, complex and simple, R\&D and delivery, et cetera. Drawing upon our empirical pool of respondents we can also observe a large variety of things that are ostensibly defined as projects, sometimes with the added comment that it does not correspond to what was taught at the last project management for researchers course. Here follows an incomplete list of projects according to everyday researchers:

- A paper, or a handful of papers to be

- The four or five year work of a PhD candidate

- $\quad$ A set of PhD candidates work for a professor

- A professors work of coaching a PhD

- $\quad$ A request for funding

- $\quad$ An effort to understand DNA sequencing

A triple post-doc with a small group of his own in molecular biology, may exemplify a very common view of projects:

"I think that, to start with, the project, the definition of the project is for me quite different from what the course was choosing, but I mean we discovered that in the first five minutes of the course. So I don't really have projects, the main aim is to establish disease models using a certain cell type and then there's lots of little smaller projects, but we call them a project that can go on and on and on and on!” Researcher, Immunology, Genetics and Pathology

On the other hand, there is a perceived need for project management, at least from the lower echelons of the research hierarchy.

"I would like to have it a little bit more structured already from the beginning. My feeling is that sometimes ideas just pop up some time along the way and maybe it's better to try to have a really good brainstorm meeting and then work from those ideas. At least it would be fun to try to do it that way and compare it to the way it's been done right now. Not sure it's better but I would like to try to have more clear phases of the project." Researcher, Neuroscience responds:

Reflecting on why this does not occur already, the same researcher rhetorically 
"Tradition? This is the way it's been done for forever. And I'm not a group leader so I can't really go in and do it my way." Researcher, Neuroscience

It is worth noting that just as the neuroscience researcher states in the above, many of the activities listed here are heavily entrenched in the tradition of academia. They are hardly new to scientific practice; and neither is the notion of project as a means for talking about at least some of these activities. What the interviews point to, however, is how the different activities are being drawn into a PM discourse in various different ways, presumably as consequence of the increasing projectification of university research.

\title{
Analysis: Talking Projects - Doing Science and Research
}

Why then does the import of traditional, industrial PM models into university research appear to be problematic? To begin with, and in contrast to conventional ideas about industrial PM, the interviews indicate that the positions of project leader and project manager/coordinator remain separate. The first position, that of the project leader, is typically held by a senior researcher; this is also the one who defines and controls the project goal, the resource allocation and the dispersion of results. The second position - referred to as the project manager, project coordinator, or work package leader - is a position that involves most or all of the administrative responsibilities associated with the project.

\begin{abstract}
"I'm doing very many of these components and am responsible for getting many things working, but I'm not formally responsible for almost anything really. 'Coz the professors they are the PIs, they're scientifically responsible; then we have the administration over here, they're doing the actual financial administration in the, that the systems and the personnel. I'm linking all this together. So it's, it's sort of a double role." Co-coordinator, Immunology, Genetics and Pathology
\end{abstract}

\begin{abstract}
"Some - we are, well, multiple project managers - can say that you pretty much cannot be, but that happens; you have to take different roles in larger projects, for example. Then it's a lot of projects where I am a leader but I may have delegated a lot of project management, or what to say, to someone else." Assistant professor, Applied Materials Science
\end{abstract}

It is the project manager who is in charge of the accounting and reporting functions of the project. This person, again drawing on the present study, is often a junior researcher, a $\mathrm{PhD}$ student or, in some cases, an enrolled administrator. Of course, such a division is not entirely foreign also to other "industrial" settings. But while it is there a question more of how professional positions are labeled, the separation observed here effectively separates the project from the PM methods and techniques - which are supposed to be guiding the process. In the university, research leaders have often outsourced practical coordination and administration to junior researchers, preferably PhD students. As this task has yet to receive any credit within the research community, and within the university organization at large, project management/coordination is usually ordered by someone in power, rather than a powerful and attractive research position in itself. An associate professor in biotoxicology, and at the same time a full time project coordinator for a very large collaborative research program on DNA, notes that the professor would typically do most of these tasks, supported by administration staff, but with PhD students often being requested to perform certain functions. And he explains his self-positioning as a future-oriented, two step strategy: nominating himself on a variety of research projects as the project coordinator carves out a place for himself as project coordinator; and although not currently valued, it may be considered increasingly important as the projectification of university research progresses.

The accommodation of PM as taxonomy, tools and techniques is generally considered to be quite awkward and uncalled for - a necessary evil, an imposed rigidity, or just not appropriate to the work at hand. One aspect that is heavily defended is the idea of research as being something qualitatively different than the particular projects subjected to PM; these projects are but components of something bigger, more stable and continuous. One way of protecting research as something different is by making a very strong distinction between 
what the researcher is doing when $\mathrm{s} /$ he is involved in getting funding and what $\mathrm{s} /$ he does when doing actual research.

One senior professor describes his frustrations with the modern financing methods, explaining how the funding agencies send out calls for applications based on what is perceived as popular science - the problem being, however, that this is often based on research presented in popular science magazines, and perhaps five years out of date by the time applications are due. Since the popular magazines gather their news from scientific journals, and since it often takes approximately two years to get something published in those scientific journals from the date of submission, a series of time lags make the calls obsolete, and not very desirable for scientists working at the research frontier.

\begin{abstract}
"So a lot of, I mean, now when I look back and see which of my papers have been cited, I mean I've published something well between 4- and 500 in the ISI based, many of them came from research that wasn't funded, where we somehow used or misused money and did something that was our own idea, we could never fund that kind of research if we apply and it goes through a reviewing process, and so I mean this is a real problem. We are forced not to do our best." Professor, Solid state physics
\end{abstract}

The notion of PM, especially by more senior researchers, is viewed as part of necessary public displays associated with obtaining and satisfying the requirements of funding agencies. Researchers admit that despite their best efforts to have research funding granted in areas of high scientific value, the necessity of financially maintaining a research department means that they often they are forced into work which is not of their highest interest. What we appear to be seeing here are thus distinct acts of separation, between Research and Projects, on the one hand, and between doing research and attending to funding requests or to funding-related reporting, on the other. The intermixing of the instrumental project canon and that of research activity is thus kept to a minimum.

As a consequence we see the research community embracing the practice of project management through $\mathrm{CV}$ maintenance, projectifying research proposals for funding as well as for reporting, whilst it, at the same time, is separating its own work from PM.

“No 'cos I don't have, we don't work like that. We don't have deadlines and we don't want to report in that way." Researcher, Neuroscience

"Sometimes one can, one can do good research, but it sometimes is controlled too much. Have to report details, how many hours have we worked and this and that. Well research is not done by the hour. It's a meaningless concept. I don't take off my head when I go home." Professor, Solid state physics

Some enthuse about the benefits PM could bring to their research and to academia, actively incorporating the tools and thought processes into their activities. The same neuroscience researcher who declared: "We don't work like that", displays her project plan whiteboard, detailing the various stages and pathways of the project work (see Picture 1).

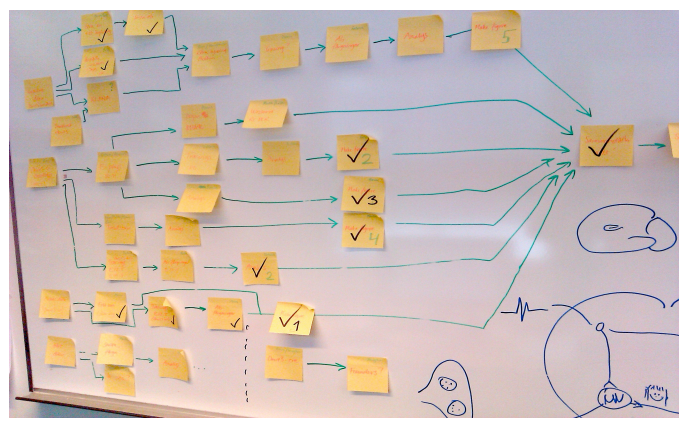

Picture 1: Activity pathways in a research laboratory. 
One reason for this distinction between university research and industrial PM could be the established norms, ideals and identities marking the researchers and their scientific practice. One such example is in the deliberate misuse of traditional PM tools in applying for funding. The accepted methodology in academia is described by one research coordinator as a backwards process. If the funding agency is known to grant a maximum of for example 2 MSEK (approximately 230 kEuro) then the application should be for this maximum amount. In the application, the researcher estimates what they could fund with this maximum amount, filling it up with people and other resources.

\section{"So it's not really, it's not made up, it's not pure inventions, but it's a, it's just thinking a} bit backwards." Coordinator, Immunology, Genetics and Pathology

Another example is the negotiation of deliverables, incorporating flexibility where possible, perhaps to reflect the perceived need for freedom in science. Based on the researchers' descriptions of the different parties to which they have to report their activities, and the various ways in which this should be done, emerges a broad and variable scale of what should be reported and in what detail. Funders of basic science, for example, are relatively understanding of research which fails to deliver exactly what was promised in the application, compared to more strategic research funding bodies, which expect detailed scientific and financial reporting, and might even question any use of funds for research that is not immediately relevant to the research question. This does not include industry financers, which have more specific questions in mind - questions that are important for their bottom lines, and might circle around the development of a new product or the improvement of an existing process, for example. Researchers also report back externally in less structured ways, such as in conference papers or published journal articles. Internally researchers might write their own reports, record data in lab books, or simply report their findings to their research group in departmental meetings or through the supervisory process.

One reason that the understanding of the project as a particular mission is generally quite vague within the research community seems to lie in the heterogeneous nature of the funding. Research efforts are often cross-funded through different means of funding. This means, for instance, that particular activity-specific funding is mixed with more general external as well as internal funding. A research groups' activities for the upcoming time period may be funded by a set of funding bodies with different requirements and interest in follow-up and control. This external pressure on the researcher and the research group from the university and financers to produce such different outputs appears to be one powerful aspect motivating the researchers' view of science as a discipline that is impossible to tame and identifying with science as inherently unruly, rather than the notion of science as a practice easily subjected to PM.

"I mean science is all about, we're all researchers, it's all about guessing really. You kind of read a lot of things and then you come up with your own idea, but it's, it might be a qualified guess, but it's still, it's kind of a guess." Researcher, Applied Materials Science

“... Because it's, this is how it works in science, you can always have hope but how it will end up, you can never know." Post-doc, Immunology, Genetics and Pathology

This acceptance that science itself - i.e., the scientific community and the forces driving its knowledge frontiers - impacts and to some extent also directs the research process, rather than some predefined project plan, leads researchers into experiencing a sense of autonomy over their work. Several researchers express the importance of having the flexibility to organize resources and perform experiments in a way that is also aligned with the opportunities they envision within the field, for creating new knowledge. In one example, a researcher explains that if the group writes in an application that they will develop a way for a certain particle to be used in a medical setting, but they then discover that the human body does in fact react fatally to it, they would be forced to consider alternatives. To do this under 
a strict regime would be difficult, whereas having a high degree of autonomy enables good science.

"To go where the results show, you never know where it will be interesting. It may of course be that you actually cannot control, really, if the project goes a certain way, you have to maybe follow it there whether you like it or not." Post-doc, Department of Medicinal Chemistry

One researcher suggests that PM is something that should come naturally to researchers through the academic environment in which they are raised, implying that they do not need to be trained in this field. The progression from being a new $\mathrm{PhD}$ to becoming a professor supposedly gifts the individual, to his view, with the capacity to seek and apply for funding, to demonstrate an understanding of research requirements and methodology, and to run both a research project and an academic environment.

"I think scientists are bred in some way that they should be capable of planning, executing and reporting whatever they do. And I think it falls quite naturally into the management skills that one would require." Senior lecturer, Nanotechnology and functional materials

The core of doing research is heavily defended through the creation of project management/coordinator positions that are low-prestige, either for $\mathrm{PhD}$ candidates to their part of departmental work or even as explicit non-research positions. The project manager or coordinator becomes heavily circumscribed or even excluded from having an influence on any daily work practice. One researcher explains the difficulty of being involved in the supervision process, and in the coordination of projects spanning several different research areas. Being asked how the researcher defines or separates his roles in such a setup, he exclaims:

"I don't! Because I think it, if I've tried to make a good supervision, it should of, the project, as it should benefit from good supervision, because the people should be then more on line with the goals, and it sort of should solve itself, I hope. And it's a time issue also, it's... I can't do it another way. I don't manage to do more. I have to sleep!"

Researcher, Immunology, Genetics and Pathology

\section{Discussion: Three Modes of Resistance to PM}

From our reading of our respondents' accounts of what they do, and how they perceive their work and their mission, we infer three interrelated modes of dealing with the projectification of university research - and to a certain extent also resisting it. Similar to Karen Ashcraft's (2005) study of how male airline pilots have resisted emasculation by embracing certain mandatory organizational changes meant to empower the rest of the crew, the first mode of resistance could be understood as partially embracing and aligning new modes of organizing with existing procedures and conceptualizations of work. Involving a strategy whereby the impact of projectification is carefully isolated and delimited, the partial nature of such accommodation is a key notion here. As we have seen above, researchers - often more senior ones - generally accept and approve of PM terminology, tools and techniques. Incorporating these components into funding applications, they structure their research projects according to a traditional linear PM logic; they provide goals as well as KPIs in line with the requirements of the various funding bodies; and they willingly promote roles and titles such as work package leaders, project managers, steering committee members, et cetera.

However, this is done with a critical distance towards these bureaucratic requirements - with the attitude that these requirements have little relevance for how the research should in fact be carried out. Hence, projectification is accommodated insofar as research promises and research outcomes are often communicated in a format that complies with PM discourse through PM-inflected funding applications, and through reporting that aligns research results with KPIs defined by various funding bodies. But since the actual research activities may well go more or less unaffected by these presentation procedures, and the roles and identities of the researchers seem to remain stable, we are only seeing a partial consent. 
The second mode of resisting, or at least limiting the impact of PM on the research activities and on the researchers themselves, is by projectifying the research administration. In larger international research collaboration programs as well as in projects with substantial funding, a particular administration team is often formed, which is responsible for communicating with funding agencies and performing a series of reporting and refinancing tasks - such as keeping accounts of how funds are spent and how results are achieved, and seeing to it that new funds are applied for. This way of organizing the research work may be understood as being thoroughly projectified inasmuch as a special organization, which is separated from the rest of the organization, is established to handle all that is related to PM. In line with Rolf Lundin and Anders Söderholm's (1995) analysis of efficient execution of temporary tasks, we see here how the part of the organization that is dedicated to PM-related activities is in fact deliberately isolated from everyday practice. The PM discourse is handled, ironically enough, through planned isolation of that which it itself imposes on the scientific community - by excluding its task as well as the team dedicated to its duties from the day-today business of the permanent research organization. As such, the tendency of increased projectification is met not only by a partial consent with respect to how research achievements are presented and reported to financiers, but also by generating a special purpose organization - a project - that is separated from the daily research business (turning, in a sense, a more critical strand of project management theory back on the hegemonizing PM discourse).

Third, and closely associated with the two modes of resistance discussed above, we can also observe a powerful counter-activity through an increased division of labor. Several people interviewed tell a story of slowly drifting out of research and into more and more purified forms of project administration. What we appear to be seeing here is thus also a gradual production of a new professional species within academia, with researchers increasingly being separated from research administrators. Although we would not go so far as to claim that this leaves the research profession entirely unaffected by the import of PM discourse, the diverging professional roles do appear to carve out a space where researchers keep on doing typical research work, whereas the new breed of project administrators (often youngish researchers with diminishing senior support and/or funding) handle the project management talk.

Now, an implicit assumption underlying all three modes of resistance discussed above is that a number of professional norms and ideals are regulating scientific research, and that the projectification of academia primarily relates to: 1 ) the norm/ideal of conducting openended explorative work in a disinterested manner and with a certain skepticism towards preestablished principles and beliefs; and 2) the norm/ideal of conducting bureaucratic rulebased work in accordance with established protocols and with predefined findings and deliverables in mind. While these norms are in no way understood as the only regulating forces within the university, the observations presented here nevertheless indicate that the projectification of university research mainly plays on and plays into the latter administrative norm/ideal. However, they also indicate that the actors who are thereby driven to specialize in talking the talk of the funding agencies also enable the continued existence of the former research norm/ideal; this by allowing explorative and open-ended work to take place in the background in a relatively unhindered manner. Conversely, and somewhat cynically, the senior researchers who are heading large research operations and defending the view of research being open-ended and exploratory, also appear to pave the way for a competent but governable research administration by providing it with appropriate people; with relatively few $\mathrm{PhDs}$ being expected to survive in research long enough to make it to a professorship, established seniors are perpetuating the idea that added competencies - project management skills among them - make out a desirable merit for sustaining a career in the university, pushing those without enough funding to establish their own research groups into the administrative realm.

While the dynamics discussed in the above have been read out of the many different accounts provided by the respondents, the processes through which projectification appears to reproduce and reorder established norms/ideals, and contribute to diverging professional roles, certainly merit further attention from organizational research. For it is important to 
keep in mind that the present study has inquired into the perceptions of a PM discourse that has entered the university setting in recent years, and analyzed some organizational consequences of such developments at UU. It has not inquired into the effectiveness of PM tools and techniques in these settings, or how scientific results and the quality thereof may have been affected by the emergence of PM discourse in university research; and it has not looked directly at how research practices - together with the norms and ideals guiding them - may actually have been transformed under the impact of PM discourse. As a complement to the present study, the project management field could certainly benefit from empirical research that would further address the many different and sometimes contradictory discourses (along with the norms and ideals they convey) at work in different research settings - empirical research that would take an interest in how these discourses contribute to shaping work practices and research outcomes, as well as the identities or self-perceptions of those subjected to them, in a broader range of settings; this with a particularly keen eye to how PM discourse intervenes in such processes.

\section{Closing Remarks: A Front- and a Backstage of University Research?}

To finish off this tour of projectified university research, there are nevertheless a number of tentative conclusions to be drawn. First of all has PM, as a disciplining force, yet to significantly affect the daily research practices. Despite its marginal effect on everyday research activities and future research plans, however, the impact of an industrial projectification logic is clearly noticeable on the organization of research. While PM practices are neither embraced nor actively resented - at least not in the traditional sense of active or passive work place resistance, i.e., by means of old-school class struggle or subtle but nevertheless antagonistic interpersonal means such as irony, svejkism, flannelling or footdragging (see, e.g., Fleming \& Sewell, 2002) - their power is rather deflected by separating the presentation of research from its practice. As such, control appears to be fended off by means of carefully orchestrated acts of consent (cf. Ashcraft, 2005). The taxonomies, tools and techniques (that are being) imposed upon the research are partially accommodated, incorporated into research applications and into reporting, but much less so in daily research routines. The permanent research organizations carrying these routines are being separated from project organizations that formally deal with PM-related activities. And the labor that is involved is characterized by a division, which appears to be giving rise to a new kind of administrative professionals within university research.

Second, these three interrelated modes or dimensions of resistance - partial consent or accommodation, the permanent organization being separated from the project organization, and the division of labor - could be said to result in a front-stage and a backstage of university research. The front-stage, as Erving Goffman (1959) have highlighted, is carefully orchestrated according to certain specific norms, values, and expectations; it is open to, and entirely dependent on an audience, and the actors on stage provide an experience in accordance with the expectations of those at the receiving end (see also Guillet de Monthoux, 2004; Manning, 2008). Just as the waiters in a restaurant are governed by norms of how to behave on the dining room floor, acting within these constraints to provide a fitting and stable experience around a meal they did not produce, so do the actors on the front-stage of academia shape how the scientific work conducted by researchers and professors in the university is presented and delivered to its financial stakeholders. What goes on behind the curtain, or within the laboratory, may well be a different matter, however. But as long as the transfer between the front and the backstage is carefully managed, the staged performance will cover up any discrepancies, and make sure that it answers to the expectations of those who have invested it. Now, in projectified university research, talking about future research (in funding applications, for instance) and about research that has been conducted (in reporting results and analyses, for instance) becomes part of the front-stage, and so do other PM-related activities. Here research is described and administered - rather than managed - by coordinators and administrators with a $\mathrm{PhD}$ position or a $\mathrm{PhD}$ degree. However, those who are conducting the actual research tend to withdraw into the private and opaque area of backstage research, which continues to be pursued on a daily basis, managed 
and upheld by established research leaders. The ways of managing different research groups are quite diverse moreover, and closely associated with the styles and personalities of the senior research leaders. A telling example of this suggested split between front-stage and backstage is reflected by an assistant professor in neurobiology, who in response to the question of whether she uses the funding application for actually conducting her research, either as a project plan or a guideline for the work, candidly exclaims: "No. That's used when I apply for money, and then each year I have to follow up and present to them which goals I achieved in my project plan, so then I go through it again, and I report back to the ones that give me money."

From the interview accounts encountered in the present study, one could only speculate, moreover, as to what extent the systematic staging of a front-end may in fact have impacted the gap between a public and a private research agenda. What we can conclude is that the PM discourse appears to have played a part in exercising researchers to carefully manage and keep separate their different stage performances - thus increasing the opacity of what researchers really desire and how they go about pursuing these ends. Allowing ourselves to remain on a somewhat speculative track, we interpret the stability and functionality of the front-stage-backstage construct as resting on a tacit agreement between the research community and a number of front-stage counterparts - such as funding agencies, policymakers and other stakeholders - that there is a certain discrepancy between what is being said and what is being done. For instance, the Swedish Research Council, from which the application instructions presented earlier were taken, requires well-organized applications according to PM 101. However, little or no reporting is required once a funding request is approved. Our comprehension of this set-up is that there is not only a mutual understanding of how funding is generally distributed, but also that there is a mutual understanding of the discrepancy between how research is planned and presented, and how it is actually conducted.

These conclusions raise several questions with regard to the efforts of industrializing or rationalizing research by means of contemporary management tools and techniques. As for the question of efficient usage of scarce funds to achieve higher yields, it has fallen outside the present study, and the argument for more or less projectification of research is far from settled, on that account. However, returning to the initial discussion with Hodgson (2002; 2005) on the disciplining powers of the PM liturgy, we can see that the unintended individual and organizational consequences of being subjected to it appears to be somewhat more complex, far-reaching and also disconcerting than his work implies. In line with Hodgson's argument, one such side-effect generated by accommodating and resisting the PM discourse is the emergence of what may possibly become a new profession within the university - one that also implies a new hierarchical order. But even though the competence and the experiences associated with this emerging profession are sometimes promoted as a virtue within the university, it does in fact appear to be low status and tie up young academics in administrative duties - a profession to which young academics are sacrificed when resources and senior support are in decline, and they are no longer in a position to support themselves as active researchers. Since not all academics can or should remain active researchers, this may perhaps seem to be of little concern. From an institutional point of view, it might even be perceived as an acceptable price to pay in order to defend research practices from becoming rationalized and disciplined through the PM onslaught - even though moving out from the permanent research organization into a projectified support organization often means a step further away from influence, careers and the decision-making strategic apex for the individual (Courpasson \& Clegg, 2006). To our view, however, the institutionalization of front-stage guardians needs to be further analyzed, discussed and evaluated before this new and emerging order is accepted and incorporated into the workings of university research; and it needs to be so with respect to individual consequences as well as organizational/institutional effects.

For the separation of the PM organizations from the permanent research organizations, which is also involved in the institutionalization of a new professional role, does indeed prompt the question of how the projectification process may unfold on an organizational/institutional level. In identifying this organizational divide, the present 
analysis has somewhat accidentally picked up on and indeed also acknowledged Christophe Midler's (1995: 374) call to further study "the evolution of the knowledge-oriented permanent organizations (or institutions) coupled with temporary product-oriented organizations". To Midler, this relationship between permanent and temporary organization makes out a central component in an evolutionary projectification process, through which project teams had been gaining an increasing degree of autonomy and power vis-à-vis stable organizational logics over a thirty-year period within the French automotive industry. Having gone from informal project coordination within functional organizations in the $1960 \mathrm{~s}$, to centralized project coordination in the 1970 's, Renault developed an alternative project management structure in the late 1980's - one that to Midler's analysis was characterized by increasing degrees of autonomy for the project teams, and that led to a situation in the 1990's where temporary intra-organizational structures had become empowered enough to transform the permanent structures and processes of the company. While Midler suggests that this may well imply a control dilemma in the short term, he also points to how it makes for a more deep-seated organizational and societal challenge in the long term; this, insofar as it calls for alternative stable organizational/social logics to balance and support, and to some extent also counteract, the temporary organizations. Giving a few clues as to what such logics might draw/build upon, Midler (1995: 374) mentions "specific long-term stable social identities or relationship" that may support "the mobility, uncertainty and stress of temporary adventures in innovation projects".

Looking at the projectification of university research analyzed and discussed above in light of Midler's (1995) evolutionary perspective, it becomes clear that there is still some way to go before the emerging PM profession will reach the autonomy and empowerment characteristic of Midler's later stages (if, at all, things are unfolding in such a direction). And the accommodation and the resistance of the PM discourse appears, on the one hand, to be stalling such a development by down-grading and separating the PM-related activities, together with the people handling them. On the other hand, however, this same division may well be sowing the seed for increased autonomy and increased influence in the long term on part of the PM administrators; with increased specialization and continuity in this line of work, and with administrators taking on this role also in research projects that lie beyond their scientific expertise, one can easily imagine them developing into a bureaucratic cadre through which much research funding (the majority?) soon must pass - one that has considerable impact on the distribution of research funds by virtue of knowing application and reporting routines, as well as the demands and expectations of the funding bodies. With large-scale research projects funded by the EU being on the rise (see, e.g., Gilbert, 2012), often with substantial financial means dedicated to PM, this kind of development may indeed be less of a fantasy than we think. UU's involvement in the European Institute of Technology - which is part of Horizon 2020: The EU Framework Programme for Research and Innovation, and superseding the Commission's Seventh Framework Programme - is already employing several PhDs with post-doctoral scientific merits as full-time project mangers and coordinators. Being more influenced by industrial PM and traditional managerialist thinking than any other research and innovation program that we have ourselves come across, our own backstage experience of conducting work within one of its Knowledge and Innovation Communities indicate that the bureaucratic routines are so strong and unbendable that any discrepancies between the front and the backstage are made virtually impossible - making the funding all but appealing, and making research and innovation projects collapse under this regime. What we are potentially seeing here, is thus a process through which that which was supposed to be the cure against bureaucracy - namely PM - has generated a bureaucracy so powerful that the research routine is made almost impossible; PM thus emerges as a pharmakon, returning more as a poison than a remedy.

In times when increasing numbers of academics have to fight for funds that are not increasing proportionally, it seems somewhat problematic to argue for academic and artistic freedom within the university; such arguments are easily misinterpreted as juvenile complaints of a spoiled profession. The tension between accountability and structuration, on one side, and the researcher's individualistic freedom, on the other, will probably remain indefinitely - and contribute to upholding a front- and a backstage of research. To our view, 
however, this tension could be mitigated. But perhaps not so much by opposing the process of projectification itself, as the way in which it has come to turn on the most widely spread PM discourse, and its linear and instrumental perspective on development processes, which leaves room only for a projectification that follows this format. This, while indeed the openended and iterative work processes and the opaque deliveries involved for instance in software development, which have effectively motivated alternative project management paradigms, also seem to characterize much university research - and possibly could make out a model that is better suited for managing scientific work.

At any rate, the projectification movement sweeping across university research should take seriously Sylvain Lenfle's (2008) distinction between projects for which the objectives as well as the constraints may be clearly defined beforehand, and whose organization exploits existing competences, and projects for which the goals as well as the resources required are difficult (if not impossible) to specify beforehand, and which circle around exploration (see also Loch et al. 2006; Shenhar \& Dvir, 2007; Lenfle \& Loch, 2010); it should take seriously his lesson to be attentive to the situation when managing projects in innovative domains, and not be afraid to adapt tools and techniques appropriately. It should be aware that the notion of project stems from the latin pro and iacio, meaning to cast forth or throw ahead, and that projects which deal with exploratory tasks are - in Lenfle's (2008) words - more "a way to construct the future and to break with past routines", than a standardized set of management tools. Hence, a projectification of university research should arguably call for tools that acknowledge the processual nature of venturing into the unknowns, tools adjusted to a process whereby directions as well as deliverables are under constant reformulation, and the guiding questions as well as the contributions may often only be formulated retroactively.

\section{References}

Adler, P. (2001), "Market, hierarchy, and trust: the knowledge economy and the future of capitalism”, Organization Science, Vol. 12 No. 2, pp. 215-34.

Ashcraft, K. (2005), "Resistance through consent? Occupational identity, organizational form, and the maintenance of masculinity among commercial airline pilots", Management Communication Quarterly, Vol. 19 No. 1, pp. 67-90.

Barker, J.R. (1993), "Tightening the iron cage: concertive control in self-managing teams", Administrative Science Quarterly, Vol. 38 No.3, pp. 408-437.

Becher, T. and Kogan, M. (1992), Process and Structure in Higher Education (2:nd Edition), Routledge, London.

Benveniste, G. (1994), Twenty-first Century Organization: Analyzing Current Trends, Jossey Bass, San Francisco, CA.

Clark, K., and Wheelwright, S. (1992), “Organizing and Leading Heavyweight Development Teams”, California Management Review, Vol. 34 No. 3, pp. 9-28.

Courpasson, D. and Clegg, S. (2006), "Dissolving the Iron Cages? Tocqueville, Michels, Bureaucracy and the Perpetuation of Elite Power", Organization, Vol. 13 No. 3, pp. 319-43.

Etzioni, A. (1964), Modern Organizations, Prentice Hall, Englewood Cliffs, NJ.

Fleming, P. and Sewell, G. (2002), "Looking for the Good Soldier, Svejk: Alternative Modalities of Resistance in the Contemporary Workplace", Sociology, Vol. 36 No. 4, pp. 85773 .

Fleming, P. and Sturdy, A. (2011), "Being Yourself in the Electronic Sweatshop: New forms of Normative Control”, Human Relations, Vol. 64 No. 2, pp. 177-200.

Gilbert, N. (2012), "EU battles over research billions: Politicians will spend the next few months negotiating cuts to Horizon 2020's budget”, Nature, Vol. 489 No. 7415, pp: 188-9.

Goffman, E. (1959), The Presentation of Self in Everyday Life, Doubleday Anchor Books, 


\section{Garden City, NY.}

Guillet de Monthoux, P. (2004), The Art Firm: Aesthetic Management and Metaphysical Marketing, Stanford Business Books, Stanford, CA.

Henkel, M. (2005), “Academic Identity and Autonomy Revisited”, Bleiklie, I., Henkel, M. (Eds.), Governing Knowledge: A Study of Continuity and Change in Higher Education, Springer-Verlag, Berlin/Heidelberg, pp. 145-65.

Henkel, M. (2007), "Can academic autonomy survive in the knowledge society? A perspective from Britain”, Higher Education Research \& Development, Vol. 26 No. 1, pp. 87-99.

Hodgson, D. (2002), "Disciplining the professional: the case of project management", Journal of Management Studies, Vol. 39 No. 6, pp. 803-20.

Hodgson, D. (2005), "Putting on a professional performance: performativity, subversion and project management", Organization, Vol. 12 No. 1, pp. 51-68.

HSV (2011), “Universitet \& högskolor: Högskoleverkets årsrapport 2011” (eng. "Universities and university colleges: Yearly report from the Swedish National Agency for Higher Education, 2011”), Högskoleverkets rapportserie, 2011:8 R, Swedish National Agency for Higher Education.

Kanter, R.M. (1990), When Giants Learn to Dance, Unwin Hyman, London.

Kunda, G. (1992), Engineering Culture, Temple University Press, Philadelphia, PA.

Lenfle, S. (2008), "Exploration and project management", International Journal of Project Management, Vol. 26 No. 6, pp. 469-78.

Lenfle, S. and Loch, C. (2010), "Lost Roots: How Project Management Came to Emphasize Control Over Flexibility and Novelty", California Management Review, Vol. 53 No. 1, pp. 3255 .

Loch, C., DeMeyer, A. and Pich, M. (2006), Managing the unknown. A new approach to managing high uncertainty and risks in projects, John Wiley \& Sons, Inc., Hooboken, New Jersey.

Lundin, R. and Söderholm, A. (1995), “A theory of the temporary organization”, Scandinavian Journal of Management, Vol. 11 No. 4, pp. 437-55.

Manning, P. (2008), “Goffman on Organizations", Organization Studies, Vol. 29 No. 5, pp. 677-699.

Maravelias, C. (2003), "Post-bureaucracy - control through professional freedom", Journal of Organizational Change Management, Vol. 16 No. 5, pp. 547-66.

Metcalfe, B. (1997), "Project management system design: a social and organizational analysis", International Journal of Production Economics, Vol. 52 No. 2, pp. 305-16.

Midler, C. (1995), “Projectification' of the Firm: The Renault Case”, Scandinavian Journal of Management, Vol. 11 No. 4, pp. 363-75.

Mintzberg, H. (1980), "Structures in 5's: A Synthesis of the Research on Organization Design”, Management Science, Vol. 26 No. 3, pp. 322-41.

Savage, C. (1996), 5th Generation Management: Co-creating through Virtual Enterprising, Dynamic Teaming, and Knowledge Networking, Butterworth Heinemann, Boston, MA.

Shenhar, A. and Dvir, D. (2007), Reinventing project management, Harvard Business School Press, Boston, MA.

Weber, M. (1905/2009), The Protestant Ethic and the Spirit of Capitalism. Norton \& Company, New York, NY. 